\title{
Genome-wide diversity and structure variation among lablab [Lablab purpureus (L.) Sweet] accessions and their implication in a Forage breeding program
}

\author{
Julius Pyton Sserumaga (1) - Siraj Ismail Kayondo • Abasi Kigozi • \\ Muhammad Kiggundu • Clementine Namazzi $\cdot$ Kato Walusimbi • \\ James Bugeza $\cdot$ Allen Molly $\cdot$ Swidiq Mugerwa
}

Received: 13 July 2020 / Accepted: 9 March 2021 / Published online: 19 March 2021

(C) The Author(s) 2021

\begin{abstract}
Most orphan crops have not been fully sequenced, hence we rely on genome sequences of related species to align markers to different chromosomes. This hinders their utilisation in plant population improvement programs. Utilising the advances in the science of sequencing technologies, the population structure, relatedness, and genetic diversity among accessions can be assessed quickly for better exploitation in forage breeding programs. Using DArTseq technology, we studied the genetic and structural variation in 65 Lablab purpureus (L.) Sweet conserved gene-bank accessions using 9320 DArTseqbased SNPs and 15,719 SilicoDart markers. These markers had a low discriminating ability with mean
\end{abstract}

Supplementary Information The online version contains supplementary material available at https://doi.org/10.1007/ s10722-021-01171-y.

J. P. Sserumaga $(\bowtie) \cdot$ S. I. Kayondo .

A. Kigozi · M. Kiggundu · C. Namazzi .

K. Walusimbi · J. Bugeza · A. Molly · S. Mugerwa ( $\square)$

National Agricultural Research Organization; National

Livestock Resources Research Institute,

P.O. Box 5407, Kampala, Uganda

e-mail: j.serumaga@gmail.com

S. Mugerwa

e-mail: mugerwaswidiq@gmail.com

Present Address:

S. I. Kayondo

International Institute of Tropical Agriculture, Ibadan,

Nigeria polymorphic information content (P.I.C.) of 0.14 with DArTseq-based SNPs and 0.13 with SilicoDart markers. However, the markers had a high mean call rate of 73\% with DArTseq-based SNPs and 97\% with SilicoDart markers. Analysis of molecular variance revealed a high within populations variance $(99.4 \%$ ), indicating a high gene exchange or low genetic differentiation $(\mathrm{PhiPT}=0.0057$ ) among the populations. Structure analysis showed three allelic pools in variable clusters of $\Delta K=3$ and 6 . Phylogenetic tree of lablab accessions showed three main groups with variable membership coefficients. Most pairs of accessions (40.3\%) had genetic distances between 0.10 and 0.15 for SilicoDart markers, while for DArTseq-based SNPs, (46.5\%) had genetic distances between 0.20 and 0.25 . Phylogenetic clustering and minimum spanning analysis divided the 65 accessions into three groups, irrespective of their origin. For the first time, this study produced high-density markers with good genom coverage. The utilisation of these accessions in a forage program will base on the information from molecular-based grouping. The outcomes uncovered the presence of noteworthy measure of variety in Uganda, CIAT and ILRI accessions, thus demonstrating an opportunity for further marker-trait-association studies.

Keywords Plant genetic resources - Genetic differentiation - Genetic diversity - SNP · SilicoDart 


\section{Introduction}

Dolichos lablab [Lablab purpureus (L.) Sweet] is an essential legume used as food and feed. It is assumed to have originated in Africa (Maass et al. 2005; Maass and Usongo 2007; Verdcourt 1970) and India (Ayyangar and Nambiar 1935; Shivashankar et al. 1993). It belongs to the family Fabaceae characterised as a busy semi-erect perennial herb. It is primarily a selfpollinated crop with doubled chromosome number $2 n=2 x=22$ (Goldblatt 1981; She and Jiang 2015). It is one of the diverse annual legume crop in tropical and subtropical regions worldwide (Smýkal et al. 2015). Lablab is a multipurpose crop used mainly for animal feeding as forage meal, fresh forage, straw, hay, grain, grazing, or browsing. Humans consume it's fresh leaves, immature grains, mature grains, green pods, as pharmaceutical or nutraceutical foods (Adebisi and Bosch 2004; Morris 2009; Subagio and Morita 2008). The crop is also used for soil improvement, protection and weed control (Ewansiha and Singh 2006).

In Uganda, lablab is predominantly utilised as feed for ruminants, notably cattle, served as fresh foliage. The use of lablab grain in monogastric and ruminant diets is limited due to high levels of antinutritional compounds in locally available cultivars. Furthermore, the utilisation of lablab for silage production is constrained by the incompatibility of available local cultivars with silage production equipment and difficulties in wilting the crop due to its thick moist stems. The crop's intolerance to trampling and grazing also constrains the integration of lablab into grass-dominated pasture swards under grazing systems. Regardless of its wide adaptability, diversity and aptness to tropical agricultural production systems, lablab remains underutilised (Ebert 2014; Engle and Altoveros 1999). In the effort to harness the multiple benefits of lablab and to stimulate its increased utilisation in diverse livestock production and feeding systems, the National Livestock Resources Research Institute of the National Agricultural Research Organisation of Uganda acquired lablab germplasm from the International Livestock Research Institute (ILRI), the International Centre for Tropical Agriculture (CIAT), local country collections, and assembled a group of elite accessions. This collection of elite accessions is well-thought-out as the most reliable and efficient source for the primary search of trait-specific accessions. These can be utilised for quantitative trait loci discovery, allele mining, and association mapping panel development to explore forward breeding while enhancing the genetic gains in lablab breeding for yield and its component traits.

With recent genomic technological advancement, it's now possible to examine the whole species' genome than selected regions within the genome to capture markers that contribute to complex traits (Maulana et al. 2019). Thus, it's imperative to understand the genetic relationship of new and uncharacterised accessions to effectively be utilised in the breeding pipeline (Sserumaga et al. 2019, 2014). This is possible with the help of molecular markers since their cost per data point is low, highly abundant within the genome, they are locus-specific, co-dominant, and low genotyping error rates (Rafalski 2002). Single nucleotide polymorphism (SNP) are one of the robust marker types used in diversity studies and genome-related association studies (Azmach et al. 2013; Farfan et al. 2015; Suwarno et al. 2015). However, some orphan crops like lablab have not been sequenced to the fullest. This study aimed to determine (i) the level of molecular diversity and structure among 65 gene-bank accessions using 9320 DArTseq-based SNP markers and 15,719 DArTseqbased SilicoDArT markers, (ii) the relationship among the set of accessions for better utilisation in a breeding program.

\section{Materials and methods}

Plant materials, DNA extraction and Genotyping using DArTseq platform

A total of 65 lablab gene-bank accessions acquired from ILRI and CIAT gene banks and local collections were used in the study (Table 1). Leaf tissue was collected, packaged and shipped for genotyping at Integrated Genotyping Sequence Support (IGSS) platform hosted at Bioscience for East and Central Africa (BecA)-Hub, at ILRI, Nairobi. The leaf samples were lyophilised and total DNA extracted using the DNeasy plant mini kit (250) (Qiagen Inc., Valencia, CA) as per the manufacturer's guidelines. DNA concentration and purity were determined using a Nanodrop (DeNovix DS-11 FX spectrophotometer). Extra quality check was carried out on $0.8 \%$ agarose 
Table 1 Proportion of membership of each predefined population from structure analysis $(\Delta K=3)$

\begin{tabular}{lclll}
\hline Population & Number of Individual & \multicolumn{4}{l}{ Estimated membership coefficient } \\
\cline { 3 - 5 } & & CI & CII & CIII \\
\hline CIAT gene banks (CIAT) & 39 & $0.363(14)$ & $0.106(4)$ & $0.531(21)$ \\
ILRI gene banks (ILRI) & 19 & $0.313(6)$ & $0.492(9)$ & $0.196(4)$ \\
Local Collection (UG) & 7 & $0.035(0)$ & $0.208(2)$ & $0.757(5)$ \\
\hline
\end{tabular}

gel electrophoresis with lambda DNA of $50 \mathrm{ng}$ as a marker. DNA for each sample was diluted to a required concentration range of $50-100 \mathrm{ng} / \mu \mathrm{l}$ for the DArTseq genotyping platform. After standardisation, $25 \mu \mathrm{l}$ was aliquoted into 96 well semi-skirted plates for sequencing.

Using DArTseq platform, lablab genotyping was carried out using Diversity Array Technology (http:// www.diversityarrays.com/) (Kilian et al. 2012). Digestion of $50 \mathrm{ng}$ of DNA was done using a recipe of PstI/HpaII restriction endonucleases. Products later ligated to a PstI overhang compatible with oligonucleotide adapter and sequenced using $P$ st $I$ site-specific primers on an Illumina HiSeq 2500 (Illumina). Referencing the DArTseq protocol, Short sequence fragments, SNP and SilicoDArT, markers were generated. Since there is no available full sequence of lablab bean, the sequence fragments were aligned with the Mung bean (Vigna radiata (L.) R. Wilczek) reference sequence on Ensembl (https://plants.ensembl.org/ Vigna_radiata/Info/Index). The genome-wide SNPdensity plot distribution of the markers was envisaged using the R-package CMplot (https://github.com/ YinLiLin/R-CMplot).

\section{Marker data analysis}

Genotyping by Sequence data for SNP and SilicoDArt markers distributed across the lablab genome was received from IGSS at BecA Hub. Percentage of missing data per marker, per accession, Call rates, polymorphic information content (P.I.C.) and Expected heterozygosity $(\mathrm{He})$ were calculated in DartView (http://software.kddart.com/kdxplore/ dartview/). Using TASSEL v.5.2.43 software (Bradbury et al. 2007), genotypic data was filtered with 0.05 for minor allele frequency and a minimum count of $80 \%$ for sample size. Genetic distance was computed between pair of lablab accession using identity by state similarity (I.B.S.) method in TASSELv.5.2.43. A marker based kinship matrix was then calculated between pair of lablab in dataset using TASSELv.5.2.43.

Genetic relationship and population structure

The Diversity of the lablab accessions were assessed using the model-based STRUCTURE, minimum spanning network and different diversity indices Stoddart and Taylor's G (Stoddart and Taylor 1988) and Shannon-Wiener's $H^{\prime}$ (Shannon and Weaver 1949). A multivariate model-based clustering approach, implemented in the STRUCTURE software package version 2.3.4 (Pritchard et al. 2000), was used to analyse population structure. In the model-based clustering approach, a 100,000 burn-in period was utilised, followed by 100,000 iterations. A model taking into consideration admixture and correlated allele frequencies with no information about location or population was used to deduce the right number of groups in the population of 65 accessions using posterior probabilities (qK). Ten independent runs of STRUCTURE were executed with the number of clusters set from 1 to 10 , through 10 replicates for each $\mathrm{K}$. Delta $\mathrm{K}$ was computed for each value of $\mathrm{K}$ using online software, the Structure Harvester (Evanno et al. 2005). Each accession was allocated to a given group when the extent of its genome in the cluster $(\mathrm{qK})$ was higher than an edge estimation of 50\%.

Phylogenetic analysis using unweighted pair-group mean arithmetic was performed to envisage the relationships between accessions using the $\mathrm{R}$ package Analyses of Phylogenetics and Evolution (ape) (Paradis et al. 2004). Analysis of molecular variance (AMOVA) was performed to determine the variance among populations and among accessions within populations using the $\mathrm{R}$ package poppr version 2.8.5. (Kamvar et al. 2015). Genetic differentiation among 
lablab accession populations was calculated with the $\mathrm{R}$ packages poppr version 2.8.5 and vegan version 2.0.7 (Kamvar et al. 2015; Oksanen et al. 2013), which enabled the estimation of standardised PhiPT and the allelic patterns across different populations (Meirmans 2006). An independent analysis called the minimum spanning network was used to visualise the population structure using igraph $\mathrm{R}$ package version 1.2.5. (Csardi and Nepusz 2006).

\section{Results}

Genotyping lablab accessions using Genotyping by Sequencing.
Maker Density, genetic distance and relationships

A total of 9,320 polymorphic SNPs makers were called on 65 lablab accessions with an average of two alleles detected per loci and with a mean call rate of $73 \%$. Average minor allele frequency calculated ranged from 0 to 0.09 with a mean of 0.09 . Heterozygosity per marker ranged from 0 to 0.61 , with a mean of 0.03. Polymorphic Information Content ranged from 0.02 to 0.5 , with an average of 0.14 . Genetic distance between lablab accession pairs ranged from 0.08 to 0.49 , with an average of 0.26 . The majority of lablab pairs $(46.5 \%)$ had genetic distances between 0.20 and 0.25 (Fig. 1a). Relative kinship relationship coefficients between sets of accessions ranged from 0

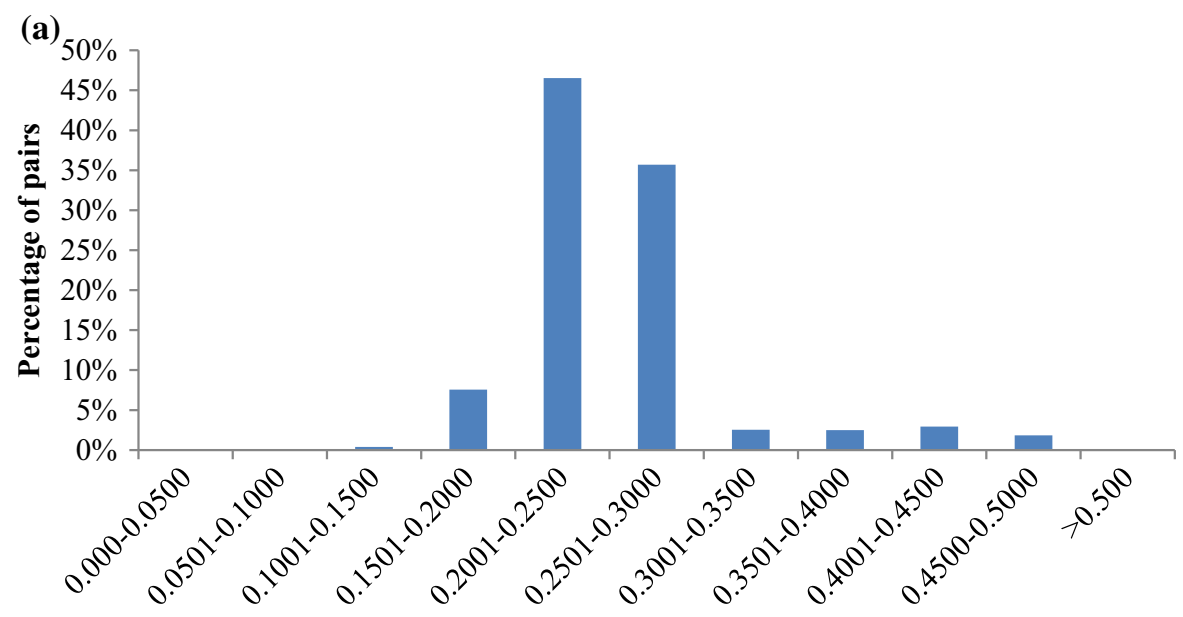

(b)

Genetic distances

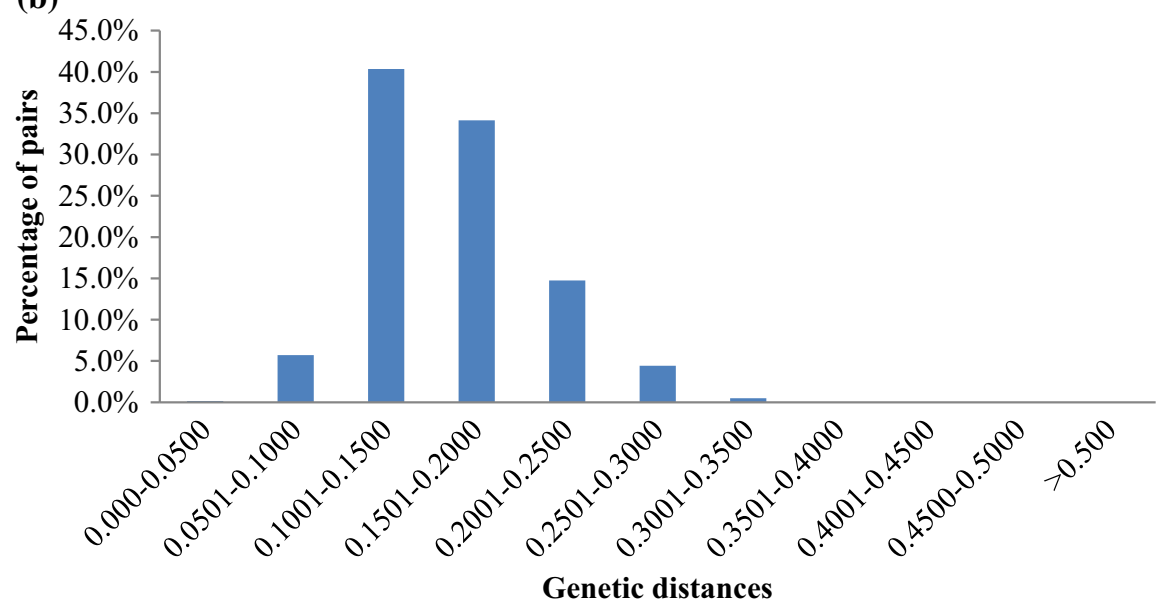

Fig. 1 a Roger's genetic distance distribution for 65 Lablab Accessions genotyped with 9320 polymorphic SNPs markers. b Roger's genetic distance distribution for 65 Lablab Accessions genotyped with 15,719 polymorphic SilicoDArT markers 
Table 2 Genotypic richness, diversity, and evenness

\begin{tabular}{lrccllllllll}
\hline Pop & N & MLG & eMLG & SE & H & G & lambda & E.5 & Hexp & Ia & rbarD \\
\hline CIAT & 39 & 39 & 10 & $0.00 \mathrm{E}+00$ & 3.66 & 39 & 0.974 & 1 & 0.313 & 127.6 & 0.00922 \\
ILRI & 19 & 19 & 10 & $2.51 \mathrm{E}-07$ & 2.94 & 19 & 0.947 & 1 & 0.304 & 926.7 & 0.05827 \\
UGA & 7 & 7 & 7 & $0.00 \mathrm{E}+00$ & 1.95 & 7 & 0.857 & 1 & 0.363 & 90.3 & 0.00913 \\
Total & 65 & 65 & 10 & $6.30 \mathrm{E}-06$ & 4.17 & 65 & 0.985 & 1 & 0.255 & 362.6 & 0.02208 \\
\hline
\end{tabular}

Pop Population name, $N$ number of individuals observed, $M L G$ number of multilocus genotypes (MLG) observed, $e M L G$ the number of expected MLG at the smallest sample size $\geq 10$ based on rarefaction, $S E$ standard error based on eMLG, $H$ Shannon-Wiener index of MLG diversity, $G$ Stoddart and Taylor's index of MLG diversity, lambda Simpson's Index, E.5 evenness, Hexp Nei's unbiased gene diversity, Ia the index of association, $r b a r D$ the standardized index of association

to 3.85 , with an average of 4.42 . The genetic differentiation among the ecotype populations (PhiPT) was low (0.0056) (Table 2).

A total of 15,719 SilicoDArT markers were called on the 65 lablab accessions, with a mean call rate of 97\%. Polymorphic Information Content ranged from 0.03 to 0.50 , with an average of 0.13 . Genetic distance between pairs of accessions ranged from 0.03 to 0.32 , with a mean of 0.16 . The majority of pairs of accessions $(40.3 \%)$ had genetic distances between 0.10 and 0.15 (Fig. 1b). The relative kinship relationship coefficient between sets of accessions ranged from 0 to 3.25 , with a mean of 3.42 .

Genome-wide SNP-density distribution plot of the markers

The SNP and SilicoDArT markers were mapped to the genome of Mungbean, because it's the specie with a sequenced genome closely related to lablab. The markers aligned per chromosome ranged from 49 to 162 for SilicoDArT, and 54 to 167 for SNPs. In both sets of markers, the largest and least number of markers mapped onto chromosome seven and three respectively. Generally, only 7\% (1025 out of $15,719)$ of the SilicoDArT markers and 13\% (1226 out of 9320) of the SNP markers mapped on the eleven chromosomes of the Mung bean genome (Fig. 2a, b).

Phylogenetic analysis

The lablab accessions clustered into three groups at 40-50 distances (Fig. 3a, b). Phylogenetic trees clustered the accessions into three subgroups (Fig. 3a, b). Results from SNP clustering revealed that Group III (46\%) consisted of more accessions than Group I
(25\%) and Group II (29\%). SilicoDArT markers clustering revealed that there were more accessions in Group II (75.4\%) than in either Group 1 (12.3\%) or III (12.3\%). Group 1 consisted more of ILRI and CIAT accessions under SNP clustering and only, Ugandan accessions were clustered in Group III. However, using SilicoDArT markers, the Uganda accessions were evenly distributed in all the 3 groups.

SNP clustering established that one ILRI accession was closely related to 15 CIAT accessions in group 1 . In group 2, 6 CIAT and 5 ILRI accessions sub grouped with one Ugandan accession. At the same time, the second sub-group comprised only CIAT accessions. In Group 3, 14 CIAT accessions sub grouped with 9 ILRI and 6 Ugandan accessions. Silico Dart marker grouping is more less like SNP clustering. The dendograms (Fig. 3a, b) indicate 3 lineages in the lablab population and similar pattern is observed in clusters generated by STRUCTURE.

Using SNPs for minimum spanning network clustering, the number of clusters detected was also 3 , but not based on their origin of the accessions (Fig. 4). The Ugandan accessions was found in two groups. Also, the network (Fig. 4) indicates the presence of 3 lineages in the lablab population, and a similar pattern is observed in clusters generated by STRUCTURE and Neighbor-Joining.

Diversity in the lablab populations

The model-based STRUCTURE, minimum spanning network methods showed the presence of the three divergent groups. The subpopulations within the 65 Lablab accessions were analysed, with the 9,320 polymorphic SNP markers in the STRUCTURE software. The highest peak of delta $\mathrm{K}$ was at $\mathrm{K}=3$ 
(Fig. 5a), was indicative of three major groups and admixed accessions. However, a second major peak at $\mathrm{K}=6$ signifies six probable subgroups (Fig. $5 \mathrm{~b}$ ). At a 0.50 membership probability threshold when $\mathrm{K}=6$, 15 accessions were assigned to Group I, two
Fig. 3 a Phylogenetic tree for 65 Accessions dependent on Rogers' genetic distance from 9320 SNP markers. b Phylogenetic tree for 65 Accessions dependent on Rogers' genetic distance from 15,719 polymorphic SilicoDArT markers

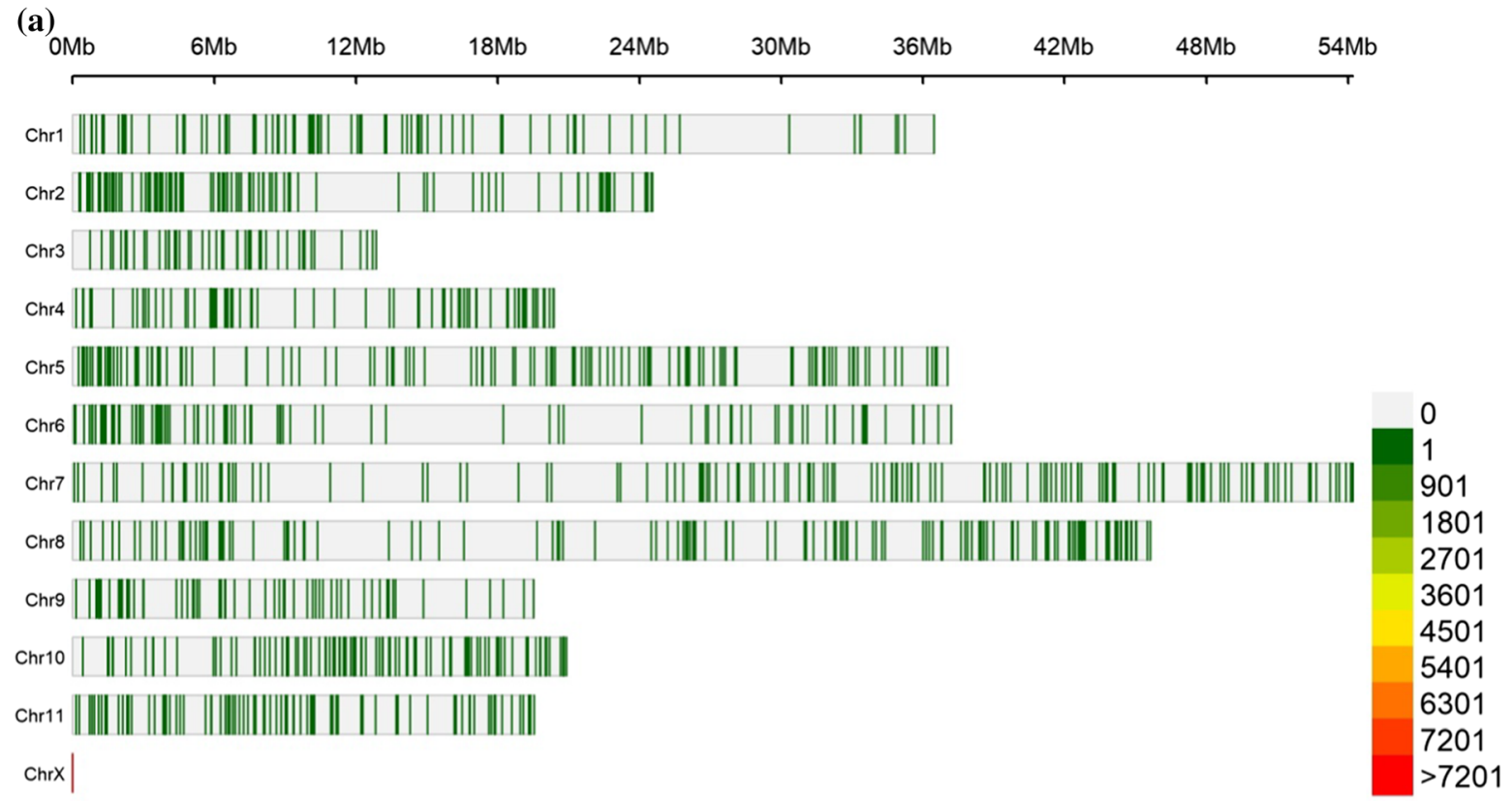

(b)

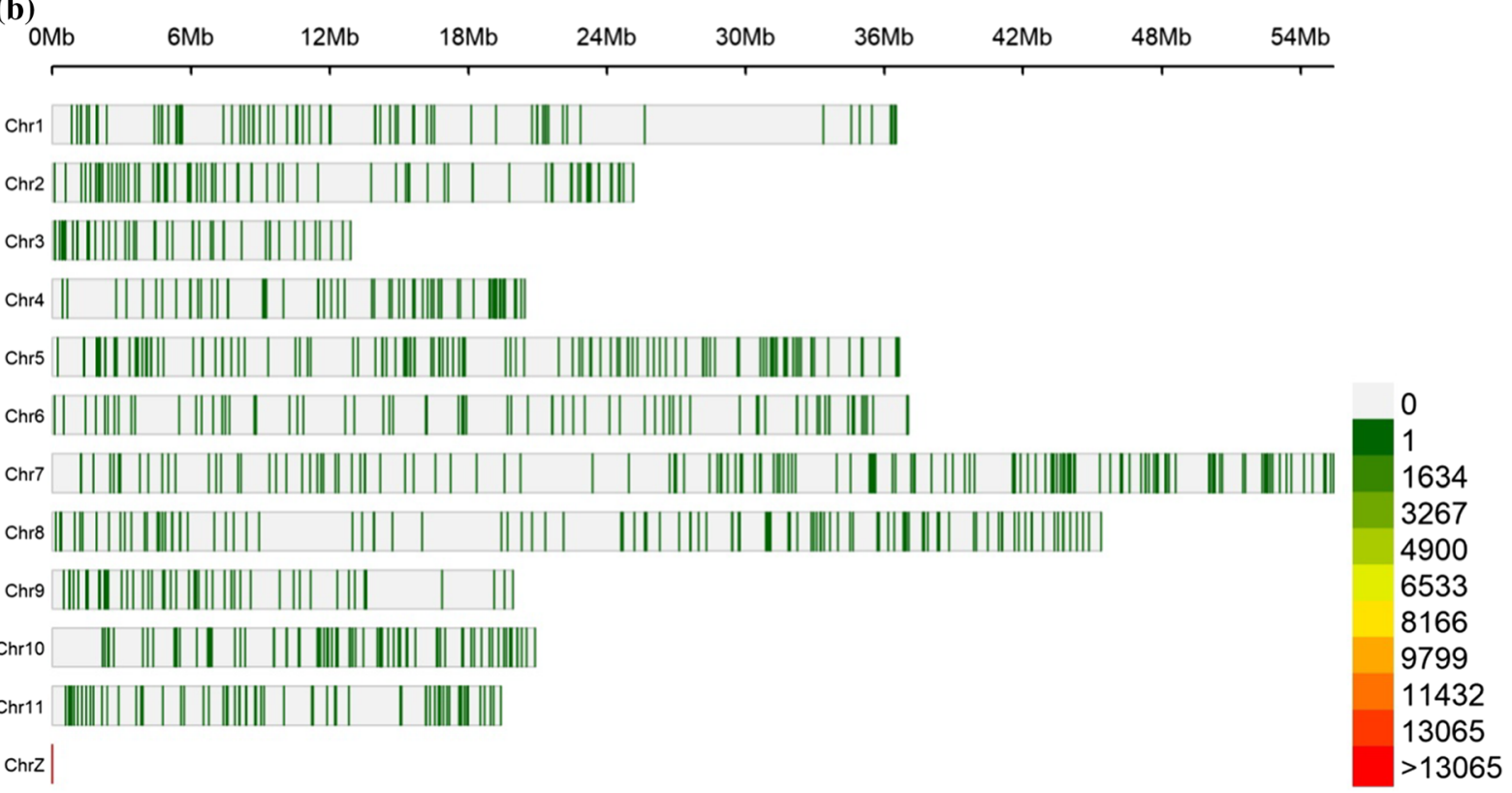

Fig. 2 a SNP density levels within $1 \mathrm{Mb}$ window size with different colors. "Chr" refers to common mung bean chromosomes with unmapped markers. b SilicoDArT Marker density levels within $1 \mathrm{Mb}$ window size with different colors. "Chz" refers to common mung bean chromosomes with unmapped markers 

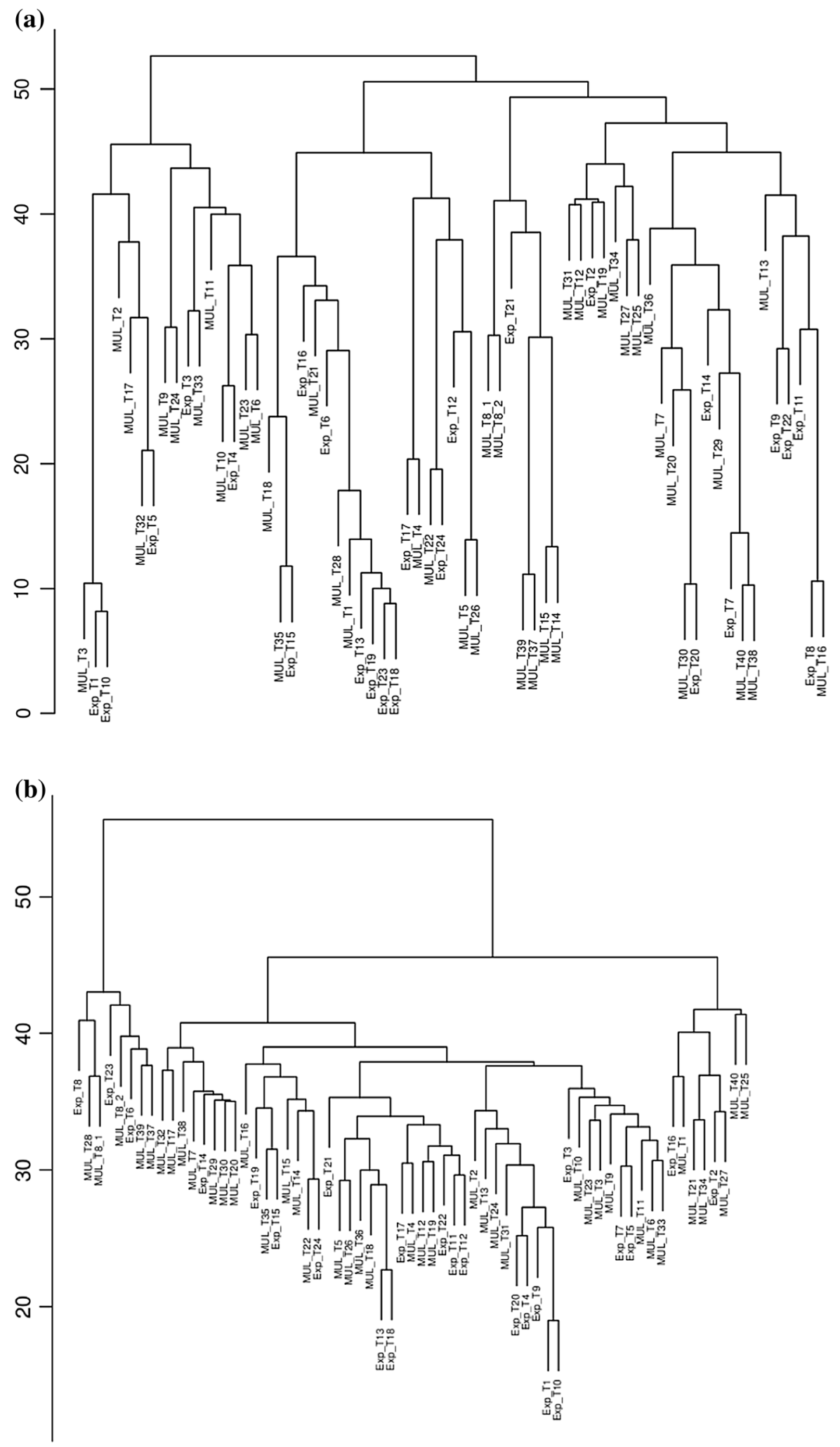
accessions to Group II, seven accessions to Group III, 14 accessions to Group IV, 12 accessions to Group V, and 15 accessions to Group VI (Fig. 5c). For $\Delta \mathrm{K}=3$, most of the accessions from CIAT, showed the greater probability of ancestral membership for cluster I and III (Table 2).

Analysis of molecular variance

AMOVA method was employed to analyse lablab populations to deduce the population differentiation using SNP markers. The AMOVA results showed that among diversity explained by $0.57 \%$, and withincluster diversity explained by $99.43 \%$ of the total variation (Table 3 ).

Allelic Diversity in the Regional Populations

The allelic diversity in three populations of lablab accessions is presented in Table 2. The number of expected M.L.G. at the smallest sample size $\geq$ ten based on rarefaction ranged from 7 (UGA) to 10

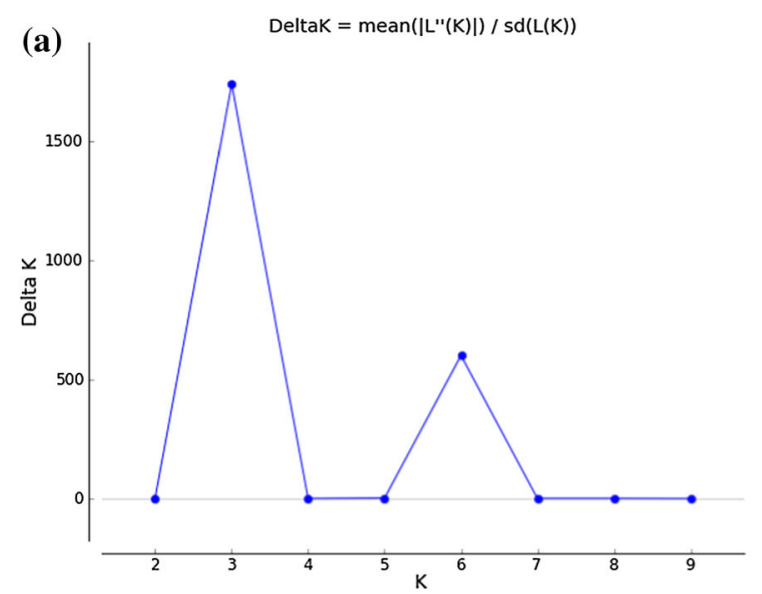

(b)

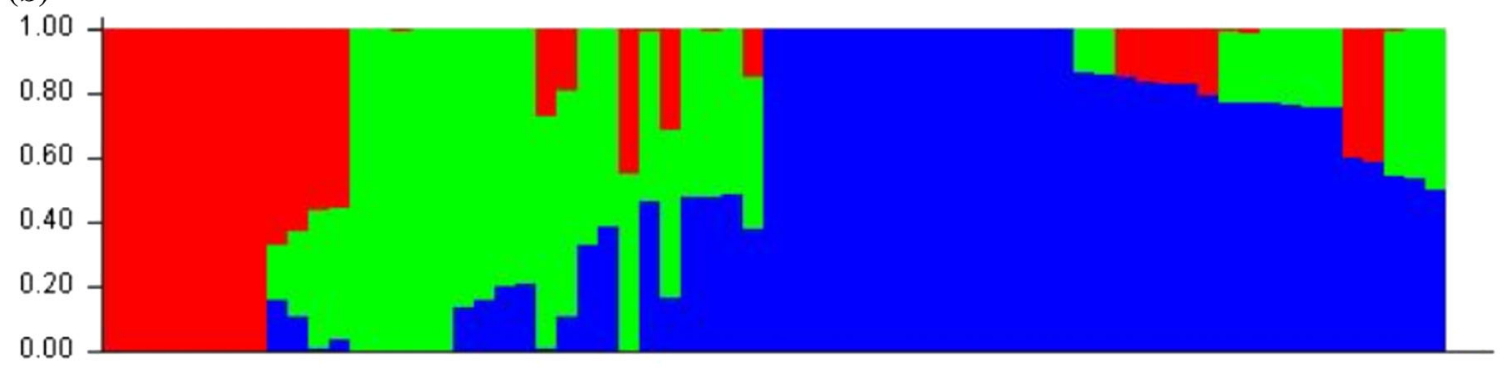

(c)

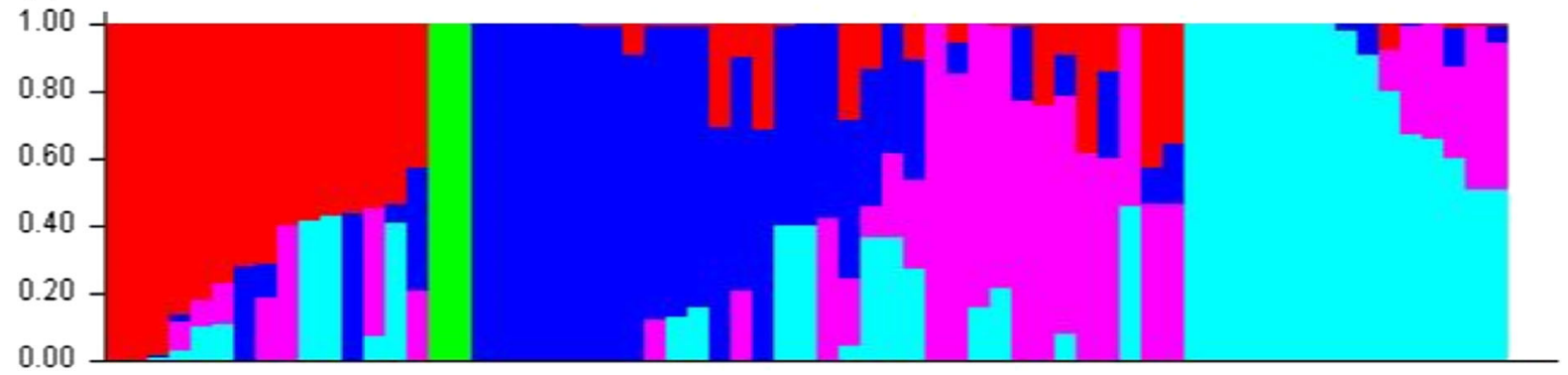

Fig. 4 Minimum spanning networks (MSN) of 65 accessions based on origin 
Table 3 Analysis of molecular variance for genetic differentiation among and with clusters of Lablab collection

\begin{tabular}{lrrrrl}
\hline Source & DF & \multicolumn{1}{l}{ SS } & MS & Est. var & $(\%)$ \\
\hline Among populations & 2 & 5205.06 & 2602.53 & 13.47 & 0.57 \\
Within populations & 62 & $146,618.48$ & 2364.81 & 2364.81 & 99.43 \\
Total & 64 & $151,823.54$ & 2372.24 & 2378.29 & 100 \\
\hline
\end{tabular}

Genetic differentiation among accession populations $(\mathrm{PhiPT})=0.0056 ; \mathrm{P}=0.142$

DF Degree of freedom, SS sum of squares, MS squares, Est. var. estimate of variance, \% percentage of total variation $\mathrm{P}$-value is based on 9999 permutations

(CIAT). We detected the highest mean genetic diversity in CIAT population $(\mathrm{H}=3.66, \mathrm{G}=39)$, while the UGA population had the least mean genetic diversity $(H=1.95, \mathrm{G}=7)$. The evenness index was equal to 1 for all accession; hence all occurred at the same frequency. The Nei's unbiased gene diversity was detected highest in UGA population $(\mathrm{Hexp}=0.363)$ and lowest in ILRI population (Hexp $=0.304)$. Diversity indices increased with increasing genotypic richness and samples size (Table 2). $H$ and $G$ increased linearly as the number of lablab accession $(\mathrm{N})$ increased (Table 2), and this was true for the $\lambda$ and $H$.

\section{Discussion}

The analysis of a lablab population's genetic structure is paramount to broaden the knowledge on the genetic base of germplasm for the breeding programs by identifying genetic pools. It enhances the utilisation and conservation of genetic resources. Although many phylogenetic studies have conducted using different markers (Mba and Tohme 2005; Venkatesha et al. 2007), has relied mainly on using low-density molecular markers (Humphry et al. 2002; Konduri et al. 2000; Patil et al. 2009; Sujithra et al. 2009; Wang et al. 2004, 2005). The discovery of genome-wide molecular markers in an organism with restricted genomic data like lablab is possible with genotyping by sequencing approaches, a cost-effective method $(\mathrm{Hu}$ et al. 2018; Kilian et al. 2012). This study presents results of the first kind of lablab diversity with advanced molecular marker technologies. We assessed the diversity and population structure in the lablab collection using genome-wide density SNP and SiliconDArT markers (Jaccoud et al. 2001; Kilian et al. 2012). Both SNP and SilcoDart markers used in this analysis resulted in broad agreement albeit varying genomic regions were studied.

Since the Lablab reference genome sequence is in the pipeline of generation, the mungbean genome sequence, was used to map genomic position and distribution of the SNP and SilicoDArT markers. Mungbean ( $2 \mathrm{n}=2 \mathrm{x}=22$ chromosomes) (Kang et al. 2014) is closely related to lablab (Humphry et al. 2002). indeed, the linkage mapping comparison results showed that mungbean was highly homologous with lablab (Humphry et al. 2002), suggesting that the two species may contrast by an inversion at a particular genomic region. However, both are believed to be all the more phylogenetically far off with the different number of chromosome (11 and 12, respectively) (Humphry et al. 2002). However, a large number of mutations have apparently accumulated after divergence despite their very similar marker orders (Humphry et al. 2002). It was this significant level of homology observed by Humphry et al. (2002) between mungbean and lablab that allowed us to use the mungbean genome as reference. The genomewide mapping presented the marker distribution and density with most markers located at the peripheral chromosome arms ends, as Kang et al. (2014) reported in mungbean. However, only $7 \%$ of the SilicoDArT and $33 \%$ of the SNP markers were able to map to the mungbean genome's seven chromosomes.

Observed clustering implied a wide range of genetic diversity within the L. purpureus accessions. Using selected SilicoDart and SNP markers which were distributed across the genome and highly polymorphic makes this study the first of its kind and more robust than earlier reports with low density marker sets like amplified fragment length polymorphism. This study's results are consistent with previous reports on genetic diversity of collections using agro- 
POPULATION

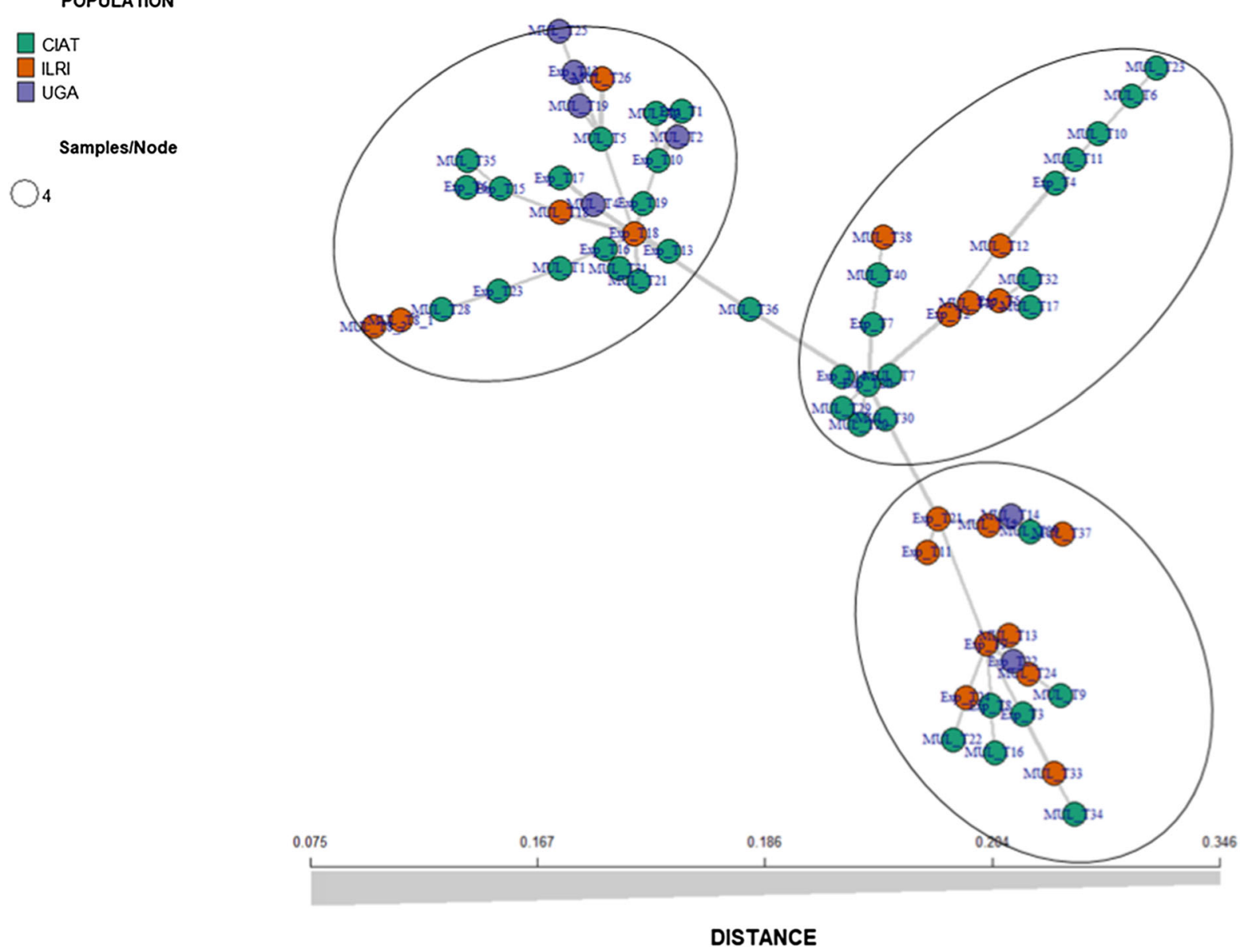

Fig. 5 a Changes in Delta $\mathrm{K}$ with number of subpopulations. b Population structure among individuals with $\mathrm{K}=3$. $\mathbf{c}$ Population structure among individuals with $\mathrm{K}=6$

morphological, physiological and molecular variables (Basavarajappa and Gowda 2000; Keerthi et al. 2014; Maass 2006; Parmar et al. 2013). This means that the high level of variation among the 65 lablab accessions is attributed to African origin and South America's collection related to the rich gene pool of the African landraces. In particular, Tefera (2006), showed distinction of the East African landraces from core collection selected to epitomise agro-morphological variation and a wide scope of geographic origins while studying molecular diversity assessment with Amplified fragment length polymorphisms markers. Also, the impact of gene flow and genetic drift on the variation is anticipated to be low as lablab is predominantly self-pollinated.
However, the results are contrary to Venkatesha et al. (2007) who used AFLP markers to study the diversity of 78 Lablab purpureus accessions and reported very little genetic diversity within Lablab purpureus accessions. In addition, Sultana et al. (2000) reported that 20 landraces studied by randomly amplified polymorphic DNA markers were similar and related to a large portion of the 60 accessions received from Australia than to those of diverse African origins. It seems that labalab in southern Asia is less diverse than that from Africa even though there is impressive agro-morphological variation (Maass et al. 2010).

The clustering of the UGA materials from Uganda, ILRI and CIAT appeared to be based on geographical origin. This is consistent with Venkatesha et al. 
(2007)'s findings, who reported difference in clustering between southern Indian germplasm collections compared to a set accession from other worldwide germplasm collections that included African accessions. Group 1 consisted more of ILRI and CIAT accessions under SNP clustering but using SilicoDArT markers, the Uganda accessions were evenly distributed in all the 3 groups. This might be due to the type of markers used that is, either dominant markers (SilicoDArT) and co-dominant markers (SNP) (Jaccoud et al. 2001; Kilian et al. 2012).

Analysis of molecular variance showed a high contribution of within-population difference to the total variation implying a high genetic diversity among accessions. This result is substantiated by a low level of genetic variation among the populations, a high pair-wise genetic distance of most accession pairs, and fair representation of accession from all sources in structure analysis clusters (particularly in $\Delta K=3$ ). Such difference among the accessions is anticipated due to the self-pollinated reproduction mode in favor of maternal accession regardless of heterozygosity level (Kukade and Tidke 2014; Shrikrishna and Ramesh 2020; Vaijayanthi et al. 2019). The partitioning of molecular variations for the accession population was similar to those reported in previous studies (Humphry et al. 2002; Konduri et al. 2000; Maass et al. 2005; Sujithra et al. 2009; Tefera 2006; Wang et al. 2004). In agreement with the STRUCTURE analysis, NJ tree and minimum spanning analysis showed accession in three distinct groups, but the membership coefficient differed between two analyses. Accessions in group 1, 2 and 3 that clustered exclusive of improved cultivars may require further study to know where they belong, because they could be possessing unique traits of agricultural importance. These observations signify high level of genetic diversity of accessions due to high gene diversity. This is because many Lablab species occur naturally in Africa, a region that represents a center of diversity of the genus (Maass et al. 2005; Maass and Usongo, 2007; Verdcourt 1970).

Our study revealed a high genetic diversity in lablab accessions and their high utility in improvement programs for economic importance traits such as high biomass production, drought tolerance, and pest and diseases resistance. Crosses of distantly related ecotypes could be an excellent strategy to broaden the genetic base. The Lablab genome's complexity, limited understanding of functional genomics of different genes, and morphological agility within and between the species has limited the pace of Lablab breeding. Therefore, there is a need to enrich the current understanding of Lablab biology and promote the integrated use of conventional and molecular breeding to exploit genetic resources from this collection and those available elsewhere. In addition, characterisation of selected accessions for morphological traits in multiple location may yield superior cultivars for commercial cultivation.

\section{Conclusions}

The genetic diversity and structure of lablab accessions deduced in this study serve as key findings that can be utilised to guide effective management, exploitation, and improvement of accessions to design genetic and marker-trait association studies. The SNP and SilicoDArT markers used in our study, with unification with S.S.R. and SNP markers developed by Konduri et al. (2000), Humphry et al. (2002), Maass et al. (2005), Wang et al. (2004), Tefera (2006) and Sujithra et al. (2009), can serve to heighten the data resources available for lablab improvement using marker assisted selection.

Acknowledgments The authors would also like to thank ILRI, Adisi Ababa AND CIAT Columbia for making their germplasm available for the study. Also BecA-ILRI hub for genotyping services.

Author contributions Conceptualisation, S.M. S.I.K. and J.P.S.; methodology, J.P.S., S.I.K., C.N., M.K. SM.; formal analysis, J.P.S.; investigation, J.P.S., C.N., M.K. SM.; resources, S.M.; data curation, J.P.S.; writing-original draft preparation, J.P.S.; writing-review and editing, J.P.S. S.I.K., A.K.,C.N., M.K., J.B., K.W., A.M. and S.M.; visualisation, J.P.S.; project administration, S.M. supervision, S.M.; funding acquisition, S.M., J.P.S., A.K., S.I.K All authors have read and agreed to the published version of the manuscript.

Funding This research was funded by the National Agricultural Research Organisation (NARO) through Competitive Grant Scheme [Grant Number NARO/CGS/ COHORTI2018/19]; and Bill and Melinda Gates foundation [Grant Number OPP1093174]; through Integrated Genotyping Sequence Support (IGSS) project. 


\section{Declarations}

Conflicts of interest The authors declare that they have no conflicts of interest.

Open Access This article is licensed under a Creative Commons Attribution 4.0 International License, which permits use, sharing, adaptation, distribution and reproduction in any medium or format, as long as you give appropriate credit to the original author(s) and the source, provide a link to the Creative Commons licence, and indicate if changes were made. The images or other third party material in this article are included in the article's Creative Commons licence, unless indicated otherwise in a credit line to the material. If material is not included in the article's Creative Commons licence and your intended use is not permitted by statutory regulation or exceeds the permitted use, you will need to obtain permission directly from the copyright holder. To view a copy of this licence, visit http://creativecommons.org/licenses/by/4.0/.

\section{References}

Adebisi AA, Bosch CH (2004) Lablab purpureus (L.) sweet. Plant Resour Trop Africa 2:343-348

Ayyangar GNR, Nambiar KKK (1935) Studies inDolichos lablab (Roxb.) and (L.) — The Indian field and garden bean. 1. In: Proceedings of the Indian Academy of SciencesSection B. Springer, pp 857-867

Azmach G, Gedil M, Menkir A, Spillane C (2013) Marker-trait association analysis of functional gene markers for provitamin A levels across diverse tropical yellow maize inbred lines. BMC Plant Biol 13:227. https://doi.org/10.1186/ 1471-2229-13-227

Basavarajappa PS, Gowda MB (2000) Genetic divergence among field bean (Lablab purpureus L. Sweet) cultnars of Southern Karnataka. Indian J Plant Genet Resour 13:134-137

Bradbury PJ, Zhang Z, Kroon DE, Casstevens TM, Ramdoss Y, Buckler ES (2007) TASSEL: software for association mapping of complex traits in diverse samples. Bioinformatics 23:2633-2635

Csardi G, Nepusz T (2006) The igraph software package for complex network research. Int J, Comp Syst 1695:1-9

Ebert AW (2014) Potential of underutilized traditional vegetables and legume crops to contribute to food and nutritional security, income and more sustainable production systems. Sustainability 6:319-335

Engle LM, Altoveros NC (1999) Collection, conservation and utilization of indigenous vegetables. In: Proceedings of a workshop AVRDC, Shanhua, Tainan, Taiwan, pp 16-18

Evanno G, Regnaut S, Goudet J (2005) Detecting the number of clusters of individuals using the software STRUCTURE: a simulation study. Mol Ecol 14:2611-2620. https://doi.org/ 10.1111/j.1365-294X.2005.02553.x

Ewansiha SU, Singh BB (2006) Relative drought tolerance of important herbaceous legumes and cereals in the moist and semi-arid regions of West Africa. J Food Agric Environ $4: 188$

Farfan IDB, De La Fuente GN, Murray SC, Isakeit T, Huang P-C, Warburton M, Williams P, Windham GL, Kolomiets M (2015) Genome wide association study for drought, aflatoxin resistance, and important agronomic traits of maize hybrids in the sub-tropics. PLoS ONE 10:e0117737. https://doi.org/10.1371/journal.pone.0117737

Goldblatt P (1981) Cytology and phylogeny of Leguminosae. Adv Legum Syst 427-463

Hu H, Scheben A, Edwards D (2018) Advances in integrating genomics and bioinformatics in the plant breeding pipeline. Agric 8:75. https://doi.org/10.3390/agriculture8060075

Humphry M, Konduri V, Lambrides C, Magner T, McIntyre C, Aitken E, Liu C (2002) Development of a mungbean (Vigna radiata) RFLP linkage map and its comparison with lablab (Lablab purpureus) reveals a high level of colinearity between the two genomes. Theor Appl Genet 105:160-166

Jaccoud D, Peng K, Feinstein D, Kilian A (2001) Diversity arrays: a solid state technology for sequence information independent genotyping. Nucl Acids Res 29:e25. https:// doi.org/10.1093/nar/29.4.e25

Kamvar ZN, Brooks JC, Grünwald NJ (2015) Novel R tools for analysis of genome-wide population genetic data with emphasis on clonality. Front Genet 6:208. https://doi.org/ 10.3389/fgene.2015.00208

Kang YJ, Kim SK, Kim MY, Lestari P, Kim KH, Ha B-K, Jun TH, Hwang WJ, Lee T, Lee J, Shim S, Yoon MY, Jang YE, Han KS, Taeprayoon P, Yoon N, Somta P, Tanya P, Kim KS, Gwag J-G, Moon J-K, Lee Y-H, Park B-S, Bombarely A, Doyle JJ, Jackson SA, Schafleitner R, Srinives P, Varshney RK, Lee S-H (2014) Genome sequence of mungbean and insights into evolution within Vigna species. Nat Commun 5:5443. https://doi.org/10.1038/ ncomms6443

Keerthi CM, Ramesh S, Byregowda M, Rao AM, Rajendra Prasad BS, Vaijayanthi PV (2014) Genetics of growth habit and photoperiodic response to flowering time in dolichos bean (Lablab purpureus (L.) Sweet). J Genet 93:203-206. https://doi.org/10.1007/s12041-014-0336-5

Kilian A, Wenzl P, Huttner E, Carling J, Xia L, Blois H, Caig V, Heller-Uszynska K, Jaccoud D, Hopper C (2012) Diversity arrays technology: a generic genome profiling technology on open platforms. In: Data production and analysis in population genomics. Springer, pp 67-89. https://doi.org/ 10.1007/978-1-61779-870-2_5

Konduri V, Godwin ID, Liu CJ (2000) Genetic mapping of the Lablab purpureus genome suggests the presence of'cuckoo'gene (s) in this species. Theor Appl Genet 100:866-871

Kukade SA, Tidke JA (2014) Reproductive biology of Dolichos lablab L. (Fabaceae). Indian J Plant Sci 3:22-25

Maass BL (2006) Changes in seed Morphology, Dormancy and germination from wild to cultivated hyacinth bean germplasm (Lablab purpureus: Papilionoideae). Genet Resour Crop Evol 53:1127-1135. https://doi.org/10.1007/s10722005-2782-7

Maass BL, Jamnadass RH, Hanson J, Pengelly BC (2005) Determining sources of diversity in cultivated and wild Lablab purpureus related to provenance of germplasm by using amplified fragment length polymorphism. Genet 
Resour Crop Evol 52:683-695. https://doi.org/10.1007/ s10722-003-6019-3

Maass BL, Knox MR, Venkatesha SC, Angessa TT, Ramme S, Pengelly BC (2010) Lablab purpureus - A crop lost for Africa? Trop Plant Biol 3:123-135. https://doi.org/10. 1007/s12042-010-9046-1

Maass BL, Usongo MF (2007) Changes in seed characteristics during the domestication of the lablab bean (Lablab purpureus (L.) Sweet: Papilionoideae). Aust J Agric Res 58:9-19

Maulana F, Kim K-S, Anderson JD, Sorrells ME, Butler TJ, Liu S, Baenziger PS, Byrne PF, Ma X-F (2019) Genomic selection of forage quality traits in winter wheat. Crop Sci 59:2473-2483. https://doi.org/10.2135/cropsci2018.10. 0655

Mba C, Tohme J (2005) Use of AFLP markers in surveys of plant diversity. In: Methods enzymol. Academic Press, pp 177-201. https://doi.org/10.1016/S00766879(05)95012-X

Meirmans PG (2006) Using the AMOVA framework to estimate a standardizegenetic differentiation measure. Evolution (NY) 60:2399-2402

Morris JB (2009) morphological and reproductive characterization in hyacinth bean, Lablab purpureus (L.) sweet germplasm with clinically proven nutraceutical and pharmaceutical traits for use as a medicinal food. J Diet Suppl 6:263-279. https://doi.org/10.1080/19390210903070830

Oksanen JF, Blanchet FG, Kindt R, Legendre P, Minchin PR, O'Hara RB, Simpson GL, Solymos P, Stevens MHH, Wagner H (2013) Community ecology package. R package version, 2(0)

Paradis E, Claude J, Strimmer K (2004) APE: analyses of phylogenetics and evolution in R language. Bioinformatics 20:289-290. https://doi.org/10.1093/bioinformatics/ btg 412

Parmar AM, Singh AP, Dhillon NPS, Jamwal M (2013) Genetic variability studies for morphological and yield traits in Dolichos bean (Lablab purpureus L.). World J Agric Sci 9:24-28

Patil P, Venkatesha SC, Ashok TH, Gowda TKS, Gowda MB (2009) Genetic diversity in field bean as revealed with AFLP markers. J Food Legum 22:18-22

Pritchard JK, Stephens M, Donnelly P (2000) Inference of population structure using multilocus genotype data. Genetics 155:945-959

Rafalski A (2002) Applications of single nucleotide polymorphisms in crop genetics. Curr Opin Plant Biol 5:94-100. https://doi.org/10.1016/s1369-5266(02)00240-6

Shannon CE, Weaver W (1949) The mathematical theory of communication. Illinois University Press, Urbana

She C-W, Jiang X-H (2015) Karyotype analysis of Lablab purpureus (L.) sweet using fluorochrome banding and fluorescence in situ hybridisation with rDNA probes. Czech J Genet Plant Breed 51:110-116

Shivashankar G, Kulkarni RS, Shashidhar HE, Mahishi DM (1993) Improvement of field bean. Adv Hortic 5:277-286

Shrikrishna PD, Ramesh S (2020) Visually assayable morphological descriptors-based establishment of distinctiveness [D], uniformity [U] and stability [S] of dolichos bean
(Lablab purpureus L. Sweet var. Lignosus) genotypes. Plant Genet Resour Charact Util 18:105-108. https://doi. org/10.1017/S147926212000009X

Smýkal P, Coyne CJ, Ambrose MJ, Maxted N, Schaefer H, Blair MW, Berger J, Greene SL, Nelson MN, Besharat N, Vymyslický T, Toker C, Saxena RK, Roorkiwal M, Pandey MK, Hu J, Li YH, Wang LX, Guo Y, Qiu LJ, Redden RJ, Varshney RK (2015) Legume crops phylogeny and genetic diversity for science and breeding. CRC Crit Rev Plant Sci 34:43-104. https://doi.org/10.1080/07352689.2014. 897904

Sserumaga JP, Makumbi D, Ji H, Njoroge K, Muthomi JW, Chemining'wa GN, Si-Myung L, Asea G, Kim H (2014) Molecular characterization of tropical maize inbred lines using microsatellite DNA markers. Maydica 59(3):267-274

Sserumaga JP, Makumbi D, Warburton ML, Opiyo SO, Asea G, Muwonge A, Kasozi CL (2019) Genetic diversity among tropical provitamin A maize inbred lines and implications for a biofortification program. Cereal Res Commun 47:134-144. https://doi.org/10.1556/0806.46.2018.066

Stoddart JA, Taylor JF (1988) Genotypic diversity: estimation and prediction in samples. Genetics 118:705-711

Subagio A, Morita N (2008) Effects of protein isolate from hyacinth beans (Lablab purpureus (L.) Sweet) seeds on cake characteristics. Food Sci Technol Res 14:12-17

Sujithra M, Srinivasan S, Sudhakar P (2009) Molecular diversity in certain genotypes of field bean (Lablab purpureus Var. lignosus Medikus) in relation to pod insect pest complex. Curr Biot 3:256-263

Sultana N, Ozaki Y, Okubo H (2000) The use of RAPD markers in lablab bean (Lablab purpureus (L.) Sweet) phylogeny. Bull Inst Trop Agric Kyushu Univ 23:45-51

Suwarno W, Pixley K, Palacios-Rojas N, Kaeppler S, Babu R (2015) Genome-wide association analysis reveals new targets for carotenoid biofortification in maize. Theor Appl Genet 128:851-864. https://doi.org/10.1007/s00122-0152475-3

Tefera TA (2006) Towards improved vegetable use and conservation of cowpea (Vigna unguiculata) and lablab (Lablab purpureus): agronomic and participatory evaluation in northeastern Tanzania and genetic diversity study. Cuvillier Velag, Goettingen

Vaijayanthi PV, Ramesh S (2019) Hyacinth bean (Lablab purpureus L. Sweet): Genetics, breeding and genomics. In: Advances in plant breeding strategies: legumes. Springer, pp 287-318. https://doi.org/10.1007/978-3-030-23400-3_8

Venkatesha SC, Gowda MB, Mahadevu P, Rao AM, Kim D-J, Ellis THN, Knox MR (2007) Genetic diversity within Lablab purpureus and the application of gene-specific markers from a range of legume species. Plant Genet Resour 5:154-171

Verdcourt B (1970) Lablab adans. Stud Legum III Kew Bull 24:409-411

Wang M, Gillaspie A, Newman M, Dean R, Pittman R, Morris J, Pederson G (2004) Transfer of simple sequence repeat (SSR) markers across the legume family for germplasm characterization and evaluation. Plant Genet Resour Charact Util 2:107-119 
Wang ML, Barkley NA, Yu J-K, Dean RE, Newman ML, Sorrells ME, Pederson GA (2005) Transfer of simple sequence repeat (SSR) markers from major cereal crops to minor grass species for germplasm characterization and evaluation. Plant Genet Resour 3:45-57
Publisher's Note Springer Nature remains neutral with regard to jurisdictional claims in published maps and institutional affiliations. 